\title{
A Comparative Study on the Theories of Highway Planning
}

\author{
Yuanqing Wang*
}

Traffic Transportation's Planning and Managing Institute, Xi'an Highway University, Xi'an 710064, China

ABSTRACT On the con text of traffic planning development and its application, the author analyses the theories of highway network planning and its practicalities in China. The highway network planning to conduct a comprehensive comparison of the two schools, points out the characteristics of each theory, the operation characteristics of adaptability and cost planning of regional circumstances in different sizes for easy selection of applications in the future depending on the purpose and conditions of the plan.

\section{KEYWORDS}

Highway network

Planning theories

Practice

Compare

\section{Introduction}

Chinese highway network planning theory are mainly based on traffic location method four-stage method "OD flow" basis and "non-OD flow" basis, the latter used "total control law", the widest range of applications, this article seeks to objectively these two methods of comparative analysis and multi-angle preliminary summary, pointing out problems and difficulties, to provide a research "platform" in order to further improve the future. Due to space limitations, this is no longer describes the specific content of the two methods can be found in the relevant literature.

\section{Operation of comparison}

Four-stage method originated in the road traffic volume forecasting urban transportation planning, traffic forecasting it for not much discussed outside content. Domestic road network planning extensive use of this method, but the method itself many issues yet to be resolved highway network planning. In accordance with the operating procedure "of highway network planning approach" (data collection, status assessment, development scale forecast, road network layout, road traffic volume forecasting, construction sequence schedule, evaluation) can be widely used in

Copyright $\odot 2014$ Yuanqing Wang

doi: 10.18686/utc.vli1.1

Received: February 9, 2014 Accepted: April 20, 2014; Published online: June 26, 2014

This is an open-access article distributed under the terms of the Creative Commons Attribution Unported License (http://creativecommons.org/ licenses/by-nc/4.0/), which permits unrestricted use, distribution, and reproduction in any medium, provided the original work is properly cited.

${ }^{*}$ Corresponding author: Traffic Transportation's Planning and Managing Institute, Xi'an Highway University, Xi'an 710064, China. E-mail: wyq_xian005@sina.com the domestic four-stage road network planning model system, with total control method for comparison.

\subsection{Collecting data}

Total control method requires the existing social and economic development information, road network data traffic and geometric characteristics, land planning, vehicle ownership, traffic information. Zaozhuang City, Shandong Province, the collected data shown in Table 1.

Table 1. Zaozhuang highway planning base data (data does not include OD).

\begin{tabular}{lcc}
\multicolumn{1}{c}{ Project Information } & Years & Data \\
\hline $\begin{array}{l}\text { Social and economic development data } \\
\text { (GNP, population, industrial and agricultural }\end{array}$ & $1980-1993$ & 523 \\
output, area) & & \\
Data traffic (passenger, freight and turnover) & $1980-1993$ & 52 \\
$\quad$ Vehicle ownership & $1980-1994$ & 25 \\
\multicolumn{1}{l}{ Road traffic, hierarchical structure } & $1986-1993$ & 1260 \\
\hline
\end{tabular}

In order to evaluate the accuracy of existing data and correction, please contact your local officer for errors that may exist in digital investigations, etc. have been described, we made some additional survey data reliability. In order to grasp the development trend of local socio-economic system, a collection of local economic development strategies in recent years have done research report set. Investigation time is approximately two weeks, the investigators from 3 to 5 people can be. Four-stage method in addition to the total amount of all kinds of survey method, the inquiry conducted by the roadside OD survey, in the territory of Zaozhuang set point 15, the use of labeling 12 h 50\% sampling rate method. To find out hours uniformity 
coefficient of the vehicle, on some sections of the traffic 24 h observation. Table 2 shows OD survey data situation.

Table 2. Zaozhuang OD survey data.

\begin{tabular}{cccc}
\hline OD Number & $\begin{array}{c}\text { Survey the } \\
\text { number of } \\
\text { vehicles }\end{array}$ & OD Number & $\begin{array}{c}\text { Survey the } \\
\text { number of } \\
\text { vehicles }\end{array}$ \\
\hline 011 & 623 & 289 & 1388 \\
293 & 105 & 286 & 625 \\
287 & 536 & 408 & 54 \\
291 & 182 & 285 & 528 \\
290 & 314 & 056 & 207 \\
297 & 107 & 283 & 936 \\
407 & 1242 & 057 & 128 \\
055 & 1791 & Total & 8766 \\
\hline
\end{tabular}

Note: Ask projects include models, start, end, rated passenger (tonnes) bit, in fact, manned ( $\mathrm{t}$ ), the real cargo class.

OD survey need to spend a relatively large amount of manpower and financial resources, but also for careful preparation, organization. In Zaozhuang City, for example, according to the first comprehensive analysis of the current situation of traffic, design OD distribution scheme. To consider regional traffic patterns characteristic lines and connection features, terrain features when OD distribution. Distribution point too, the survey results will be heavily distorted; distribution too, will increase the staff resources consumption, but also to increase the difficulty of data processing. Grasp only national and provincial Zaozhuang City area traffic start and end point, we need up to 15 distribution points. Each point requires public security police cooperation, the number of 8 to 12 people. In order to ensure compliance with the requirements of the investigation, told investigators advance of the two-week intensive training to master the methods of investigation. Survey of large amounts of data, form the basis of the data entered into a computer file, which in turn requires the purchase of equipment, training and specialized equipment operators, formed after the underlying data, to be made by professionals troubleshoot programming, statistics.

\subsection{Situation assessment}

Total control law according to their own evaluation system, for the calendar year statistics analysis and calculation, can reveal the status of the road network of the principal contradiction, the status of the road network adaptability evaluated.

Four stages of planning domestic law, but also basically the evaluation system, such as total control, such as crowding roads and congested road $(\mathrm{v} f \mathrm{c}>1.0)$ share and so on. The OD survey provides a wealth of data, so you can count out the OD cell composition of freight, passenger, vehicle configuration and loading rates, etc., reveal some more specific micro-phenomenon, distinguish the difference be- tween the OD cell contacts.

\subsection{Development scale forecast}

Total control law after the adoption of amendments to the calendar data analysis, using a variety of mathematical methods to predict the future of road traffic and road network total mileage, the equivalent mileage may range, and then by subjective analysis, with the greatest possible value as a future a year of "status" to complete the conversion of the static dynamic problems, and as a control, the use of linear programming for structural configuration. Since coming years to determine the upper and lower boundaries of each grade highway mileage is tentatively according to expert opinion, the output after reasonable or not is defined by subjective adjustment, the total control of the process is actually still not out of the traditional rule of thumb is An empirical model combining technology and art. The advantage is that you can choose different funds in operation in the forecast, so that experts on highway construction funding constraints situation may reach a different level configurations. In fact, the total road network construction there should be "flexible", as long as a suitable return on investment, can adopt measures to adjust the total amount of construction, but the method of adjustment shall be further standardized in the future studies.

Content in this section is not inherent in the four-stage method. In urban planning, for the vision of total road mileage also used the model to determine the method of combining and experts. Domestic law planning report four stages, in order to answer the urgent need for decisionmaking data, and generally the total mileage or highway network density predicted for grade configuration usually placed after road traffic forecast.

\subsection{Road network layout}

Total control law proposed importance layout method is a good way to use the effect. In planning practice, which not only make the most of the sections of the actual layout of the need to give instructions, but also to find some new line layout program to make up for lack of subjective experience of wiring. For the convergence line between urban Links, wiring required due to special industry, as well as transport, importance level layout of the process cannot be described by a comprehensive analysis of the current need for layout results with expert advice, which should be in future studies deepened. But it can be said that the method is a method to calculate the importance of results-based, relying on the expertise of relatively weak.

Four-phase layout method originated in the city. In urban planning, land often can be controlled within the city, forming distinctive cell or group. The links between cells, according to location theory Thüner and latecomers developed, can more easily identify the economic ties between the lines at different sites, contact wire position you can plan for the city road position. Thus, while the four-stage 
method itself has no layout theory, but in urban planning Road network layout is not difficult to solve, limited the alternative contact line determined. After the application of the four-stage method to the highway network planning, one of the greatest difficulties encountered by planners is the road network deployment. Because the development of the entire region is not as controllable as the city of the land; many transport distribution point too many options, theoretically optimal program operation are large, and cannot guarantee optimal [1]. Domestic road network planning practice, usually guesswork planners based on their experience and the development of planning area, laid several different network solutions. As an alternative, and then a different program sections traffic coming years, to evaluate the quality of the program to determine the best plan by forecasting.

\subsection{Traffic forecast}

Total control method for road traffic volume forecast has some difficulties. Because of the traffic volume of the "source" and "sinks" cannot be determined, only research in road traffic volume basis. Difficult to reflect the impact of the uneven development of regional road traffic, as well as for future network traffic is large morphological changes of each line is determined on a theoretical basis, methods of operation should continue further study. In the absence of data OD, OD though reverse thrust study abroad spent a lot of manpower, material resources, but did not reach the practical level. Generally realistic OD matrix some point traffic observations are not unique [2,3], although in small scale road network projections success [4,5], but how practical need further study in a large-scale road network.

Four-phase approach is essentially a traffic prediction method; it's all the work around the road traffic volume forecast to expand. Although there is a deviation systems and a variety of other causes of error when OD survey, the accuracy of the method is still the best method at present can be found. Research has shown that the probability distribution model in four phases has relatively strong modeling capabilities in a non-congested network. When the traffic volume is in 1000, this method is relatively accurate. When the model testing and calibration tolerances road traffic allocation and actual values, according to the size of the observed link flows value varies. Its tolerance for high and low flow section high flow section should be low. Foreign proposal on the road when the traffic is 8000 or greater than $8000 \mathrm{fh}$, the tolerance of $10 \%$; when the road traffic is $2000 \mathrm{fh}$, its tolerance of $30 \%$ or higher for small flow section may [6]. When land use information is not sufficient, the target year forecast only on historical data or trends mimic diagrams, using interpolation or extrapolation, the target year for travel by linear or non-linear method to obtain. This method is only for a short period of high prediction accuracy [7].

Due to lack of information on the area of land use in
China and the use of complex social, economic restructuring resulting in land mode change, with existing long-term distribution prediction OD distribution data is too rough, as a basis for long-term transportation planning credibility is low, But for the four stages of the recent traffic forecasting method is more accurate, it can reveal a deeper one than road traffic seated contradictions-exchange capacity between cells; and can simulate road network road traffic volume changes caused by the change.

Another difficulty lies in the four-stage method to expand the area of travel. The traditional method is to use a gravity model based on land use along the travel needs of the region were assigned. However, due to the lack of statistical information at this stage, difficult to achieve a satisfactory result.

Because of the four-stage method considers only certain land use patterns of traffic generated and failed to fully consider the impact on the promotion of the role of transportation facilities for land-use, which is another reason for the long-term traffic forecasts are not allowed. Practical experience of foreign countries shows that improving transport facilities, will inevitably lead to adjustments in the area of land use, in order to eliminate traffic jam is very difficult. Induced new transport users with improved transport facilities continue to emerge. The purpose should be to ensure transportation planning reachability between regions, in addition to the expansion of the road for traffic congestion, but more important is the control, reduce the amount of travel generated.

\subsection{Project sequence arrangement}

Total control law proposed the concept of the urgent construction projects, according to the exigencies of the size of construction projects sorted better. I believe or not to build a road to be considered in addition to road traffic, but also with sections of importance, the relevant sections of the administrative hierarchy. Highway network planning in Zaozhuang City, the definition section of the road traffic volume urgent, important sections of the administrative hierarchy and sections of a linear combination of functions. Road traffic volume, the higher the skill level required; the larger sections of importance, indicating that the road connecting node level higher; sections of the administrative hierarchy tend to characterize the size of transit traffic (traffic channel) or has important strategic significance.

Four-stage model law itself does not consider how to arrange the construction sequence, but only provides a reference for construction projects scheduled traffic. Arrangements for specific projects depending on the specific circumstances require planners camera processing. In planning practice at home and abroad, if the ratio is greater than $1 \mathrm{v} f \mathrm{c}$ sections all alterations, due to the traffic construction costs too big to handle [8-10], therefore, Specific arrangements for construction projects, but also qualita- 
tively consider the special needs of the road administrative hierarchy and military [11], but this has not integrated into the concept of "urgent degree".

\subsection{Planned road network evaluation}

Total control method using the evaluation target system has been established, the planning of the road network in each period related parameters can be calculated separately. The so-called comparative evaluation became operational quality of the road network at different times, by comparison, road traffic conditions each time to draw conclusions. Uniqueness of the road network due to the importance of the formation of the skeleton layout, so the impact of the evaluation of policy makers is to answer the future traffic quality possible scenarios, it reflects the adaptability of investment and transport development.

Four-stage evaluation method itself does not contain, and because of the layout of the theoretical aspects of the lack of planning in domestic road network, the more developed several possible scenarios simulate future scenarios of different road network, and further analysis of the quality of way network, Suggest an ideal solution, and the indicators of the program was evaluated.

\section{Theoretical characteristics}

(1) Total control method is the traditional location theory of correction application, focusing on the macro causes of transport, the relationship between the size of Town of comprehensive economic and transportation needs, and subject to funding constraints, network optimization and sorting. The method to maximize the use of existing Chinese statistics, the use of system analysis methods, planning from whole to part, in line with people's habits of mind, is a simple, low-cost system analysis method is suitable for conditions. Since there is no OD survey data, the links between nodes depends only needs to establish the degree of importance on the basis of the concept of economic volume, but it is difficult to fully take account of links between nodes due to differences in industrial structure caused by traffic forecasting is difficult to reflect this differentially, adapted to the development of a more balanced industrial structure configuration differences are not a lot of areas.

(2) Four-phase method is a method to predict road traffic simulation mode is the traditional location theory and modern decision theory combined with the product. It is from the micro to start by studying land use in certain people's travel patterns psychological attempt to grasp the trip distribution in different periods, in order to predict the future of road traffic, making construction practices with adaptation. This method is the traditional Western methods (analysis) on the specific application in transport planning, implies people's behavior in line with the principle of competitive opportunities, and thus simulate the probability of travel choice. Due to long-term land-use pat- terns, people's travel psychology is difficult to grasp, so for long-term prediction error is also large. Highway network planning practice, because China is a drastic rise in the development phase, so that the few existing data on longterm land use description forecasting more credible. Lack of information on land use model is too rough, so that the existing travel simulation unpersuasive; means for forming a statistical base year OD matrix behind, system error, leading to the establishment on the basis of predicted great chance.

(3) The two approaches are not contradictory, are two sides of the same coin. A macro view, a departure from the microscopic, is standing on the same issue from different angles considerations. More comprehensive, should the macro and micro considered together, that is, to combine the two methods, a comprehensive analysis.

(4) Both methods pursue microeconomics "supply and demand balance" (equilibrium), the pursuit of transportation construction and land use unidirectional adaptation (fitness) rather than coordination (coordination), it is a static approach, without considering traffic conditions tremendous impact on land use changes and consequent new traffic demands.

\section{Comparison of different planning periods and scope}

Chinese Highway Network Planning will generally be divided into short planning period (10 years), medium term (20 years), long-term (30 years) three periods; planning is also due to the recent 10 years, in such a distant period, planning land use and transportation facilities are there will be a significant area of change, 10 years ago predicted there will be a great error. Therefore, the four stages of prediction error values established on this basis will be obvious. Foreign research $[12,13]$ showed that only four stages of prediction accurate prediction for a short period. Thus, for long-term planning, the traffic forecasting significance of the four-stage method is not great. Highway Network Planning is not purely technical, and forecasters predict the results of the relevant parameters selected has a lot of experience selected and planners, policy levels predict future values of these parameters is very relevant. In general, different people in the same way will not get the same conclusions; the same people in different ways may get similar results. So for long-term planning should be the characteristics of different regions of departure, focus on solving distribution problems and ensure accessibility of transportation distribution points, meaning OD analysis relegated to secondary status, this time on total control method shows superiority. However, the recent road construction, four-stage application method is more advantageous. Especially when the road network built-up areas, in evaluating whether or not to build a road traffic metastasis, the fourstage method will have an important role, which is why this method is widely used in highway feasibility study.

For nationwide highway network planning, even if only 
consider larger-scale urban roads and ports have strategic significance, military site, integrated transport convergence at the workload OD survey also staggering, loss of operability. Considering from the layout point of view, the layout of the theoretical importance of total control law is an ideal choice. Thus, for a nationwide highway network planning, you can probably control about construction of mileage based on the country's investment, according to the layout and determine the total control method investment order [14].

For smaller county-wide planning of highway network planning, such as its low degree of urbanization, road construction focusing guarantee that the communication nodes, and can replace less route, then the total control method can meet the accuracy requirements. Four-stage method in this case is more convenient, but do not need a lot of work done by OD survey.

For the provincial, city and urbanized region of the county high highway network planning, both methods have applications now, there are not easy to solve. Traffic control method of predicting the presence of total lack of objectivity of the recent projects sort untold clear; the layout of the four-stage method [15].

Theory, total construction scale control is difficult to achieve. Therefore, a more appropriate approach should be to combine the two, so that from the macro, from the microscopic to grasp the plan. Which is to ensure long-term layout is reasonable, but also shows the need for construction projects recently.

\section{Cost comparison}

Total control method is not performed OD survey, so cost savings. General provincial planning costs at the municipal level of 10 million. Four-stage method was extremely costly due to the traffic survey, only level OD survey provinces, municipalities and it requires a lot of manpower, material and general planning fees ranging from 50 to 100 million.

\section{Conclusion}

In this paper, the highway network planning to conduct a comprehensive comparison of the two schools, points out the characteristics of each theory, the operation characteristics of adaptability and cost planning of regional circum- stances in different sizes for easy selection of applications in the future depending on the purpose and conditions of the plan. Theory of ongoing research programs, such as those on road traffic forecast, Cheng Sousa, letters red hi, who in the original law on the basis of the total, for a new attempt. Therefore, this article is only a summary of the status of the application stage.

\section{References}

1. Ministry of Transportation. (1990). Highway planning and design institute of highway network planning approach. Beijing: China Communications Press.

2. Zhang, L. (1993). Theories and methods of the county highway network planning Zhou. Xi'an Highway University, (3)

3. Zhou, W., \& Zhang, M. G. (1992). Evaluation and analysis of county highway. East China Highway, 3.

4. Chen, J. W. (1994). Regional trunk road network planning theory. Xi'an: Xi'an Highway University.

5. Ma, M. R. (1994). Transportation engineering. Beijing: China Communications Press.

6. Wang, W., \& Xu, J. Q. (1991). Urban transportation planning theory and methods. Beijing: China Communications Press.

7. Sheng, X. Q., \& Ci, X. W. (1991). Urban transport planning. Beijing: China Communications Press.

8. She, W. F. (1992). Urban transportation network. Chengdu: Southwest Jiaotong University Press.

9. Zou, D. C. (1985). Urban and regional planning. Beijing: China Building Industry Press.

10. JI, C. A. (1994). Ministry of Transportation a road network project in Zhejiang turn line survey Beijing. People's Republic of China Ministry of Transportation.

11. Zhou, O. D. Inference method highway traffic distribution on Beijing. China Journal of Highway, 1.

12. Mcloughlin, J. B. (1978). Urban and Regional planning. Faber Paper backs.1978

13. Papacostas, C. S. (1993). Transportation engineering and planning englewood cliffs. Prentice-Hall Inc.

14. Southeast University, Shandong Province Communications Department. (1995). Shandong Provincial Highway Network Planning Nanjing. Southeast University,

15. Ministry of Transportation Planning Department. (1996). Highway planning and design institute proceedings of a national plan three decades. Beijing Highway. 